\title{
Transplantation and Borrowing: the Spread of Northwest China’s Folk Tales in East Asia ${ }^{1}$
}

\author{
Su Yongqian ${ }^{2}$ \\ School of Chinese, Xi ‘an International Studies University
}

\begin{abstract}
The spread of northwest China's folk tales in the Donggan region of central Asia mainly includes two aspects: First, Donggan folk tales transplanted to the northwest folk tales. As the Donggan people migrated from northwest China, folk tales from northwest China were also transplanted to central Asia. In the absence of written records, these stories also mutate as they are passed down through the mouths and ears of foreign peoples. Secondly, Donggan folk tales borrowed from northwest folk tales. Some plot units in Donggan folktales are very similar to those in northwest China, but the specific characters and plot structure of the whole story are obviously different from those in northwest China. This kind of folk stories are new stories created by Donggan people who borrowed the parent story of folk stories in northwest China and recombined it with other plots. With comparative study of folk tales, the profound cultural ties between the two places can be revealed.
\end{abstract}

Keywords: Central Asia Donggan China Northwest Folk Tales

Due to the special historical origin, the folk tales of Donggan are closely related to those of northwest China. According to the investigation of the Russian Sinologist Li Fuqing, 76 of the 86 stories included in $A$ Collection of Donggan Folktales and Legends were circulated in Shaanxi, Gansu, Ningxia and Xinjiang in form of derivatives languages. However, as Li Fuqing mainly used Ding Naitong's Index of types of Chinese folk tales, Alberthua's Index of types of Chinese folk tales and Jin ronghua's Index of types of folk tales as the basis for his investigation, he failed to clearly explain to what extent these writings are similar to Donggan folk tales. There is also a lack of discussion on the specific situation of the dissemination and acceptance of these foreign languages in the Donggan region of central Asia. Based on the above questions, this paper will discuss the similarities and differences in plots and parent stories between the folk tales of Donggan in central Asia and the folk tales of northwest China.

\section{The Northwest Folk Story was Transplanted in Donggan Folk Story}

As we all know, the Donggan people in central Asia are descendants of Hui immigrants from northwest China in the late Qing dynasty. With the flow of ethnic groups, the folk stories originally spread in northwest China were also transplanted to central Asia. Because they are not written down, these stories are naturally mutated as they are passed down from generation to generation in the new cultural space through their mouth

\footnotetext{
${ }^{1}$ This paper is the phased achievement of Shaanxi social science fund project "A comparative study of folk literature in Donggan of Central Asia and Shaanxi” (project number: 2014I15).This article was funded by the program of Shanghai Jiao Tong University titled "World-class Universities and First-class Subjects", and the program of Shanghai City titled "Shanghai Social Science Research and Innovation Base: Chinese Creation Myth Studies” (2017WSH002).

2 About the author: Su Yongqian, Associate professor, School of Chinese, Xi 'an International Studies University
} 
and ears. However, through the analysis of the plot structure of folk stories in the two places, the relationship between them can be found. Due to the limitation of space, the author hereby intends to take three typical stories as examples to investigate the relationship between folk tales in the two regions.

\section{Story of Mao Ren (Hairy Man)}

To the best of the author's knowledge, in Shaanxi, Gansu, Ningxia and other places, there have been the story of Mao Ren. This kind of story usually tells: some old couple accidentally picked up a nest of wild eggs, for fear of several daughters would eat after find out, so they planned to throw their daughters into the wild. During the night, the girls were spotted by a man who tried to trick them to his home and eat them. But the girls beat the man at his own game, killed the man and then came home safe. It is worth noting that there are also stories of the same type among the Donggan people in central Asia, which are similar to those in northwest China. The author takes "A nest of wild eggs", a popular story in Longdong region of Gansu province, and "The old man took the old woman's seven daughters with him" which included in A collection of Donggan folk tales and legends by Li Fuqing, as the object, to compare the similarities and differences of the two stories and infer the origin of the above types of stories.

Unit (A): Cruel father throws away his daughter

\begin{tabular}{|l|l|}
\hline A nest of wild eggs & The old man took the old woman's seven daughters with him \\
\hline 1.The old couple and their four daughters & 1.The old couple and their seven daughters \\
\hline 2.Pick up a nest of wild eggs from the mountain & 2.The neighbor sent seven duck eggs \\
\hline 3.The old couple prepared to eat by themselves & 3.The wife is ready to let the old man eat \\
\hline 4.Was found by the daughter. Daughters ate eggs & 4.Daughters found out and ate the duck eggs \\
\hline The old couple decided to throw away their daughter & 5.The old couple decided to throw away their daughter \\
\hline Cheat daughter to the woods, the old man went home alone & 6.Cheat daughter to the desolate place, the old man went home alone \\
\hline
\end{tabular}

It can be seen that in the first unit, except for some details (such as the number of daughters, the type of egg, the place where the daughter was thrown, etc.), the two stories have exactly the same story links:

Unit (B): the woman defeat the Mao Ren (hairy man) by using strategies

\begin{tabular}{|c|c|}
\hline A nest of wild eggs & The old man took the old woman's seven daughters with him \\
\hline 1.The old man deceived his daughter & No correspondent plot \\
\hline $\begin{array}{l}\text { 2.The fifth sister was left in the woods, and the other six } \\
\text { daughters came home safe }\end{array}$ & All four daughters were left in the wild \\
\hline 3.Four sisters came to a large family (Mao Ren family) & No correspondent plot \\
\hline 4.Four sisters meet a kind assistant (grandma) & No correspondent plot \\
\hline $\begin{array}{l}\text { 5.The Gu Hu (wild fox) sister went home and couldn't find the } \\
\text { fourth daughter }\end{array}$ & $\begin{array}{l}\text { Mao Ye (fairy wild) woman jumped from the tree, cheat the } \\
\text { fifth sister }\end{array}$ \\
\hline $\begin{array}{l}\text { 6.The old woman asked the Ye Hu whether she would sleep on } \\
\text { an iron Kang or an earthen Kang }\end{array}$ & $\begin{array}{l}\text { Mao Ye woman asked the fifth sister whether she would sleep } \\
\text { on iron Kang or sleep on the earth Kang }\end{array}$ \\
\hline 7.Ye Hu sisters choose to sleep on an iron Kang (iron pot) & Mao Ye women choose to sleep on iron Kang (iron pot) \\
\hline $\begin{array}{l}\text { 8.Four girls with the help of the old woman, pressure the iron } \\
\text { pot, burned the Ye Hu sister }\end{array}$ & $\begin{array}{l}\text { The fifth sister alone pressure pot cover, burned the Mao Ye } \\
\text { woman to death }\end{array}$ \\
\hline $\begin{array}{l}\text { 9.After burning the Ye Hu sister, the four daughters lived a } \\
\text { happy life with the old woman }\end{array}$ & No correspondent plot \\
\hline $\begin{array}{l}\text { 10.The eldest daughter misses her parents and takes the cake to } \\
\text { visit her parents }\end{array}$ & No correspondent plot \\
\hline $\begin{array}{l}\text { 11.The daughters all came home to be reunited with their } \\
\text { parents }\end{array}$ & The fifth sister came home and reunited with her parents \\
\hline No correspondent plot & $\begin{array}{l}\text { The old man in the daughter's guidance, got the treasure of the } \\
\text { Mao Ye woman }\end{array}$ \\
\hline
\end{tabular}


Compared with the previous unit, the second unit has more differences. There are five corresponding plots in the two stories. In the Gansu story, there are five plots in the Donggan story cannot be found; In the Donggan story, there is a plot that cannot be found in the Gansu story. Even so, the basic elements of the second unit of both stories remain roughly the same, describing the abandoned woman outmaneuvering her fierce rival and eventually reuniting with her parents. Notably, both stories ask each other about sleeping on an "iron Kang” or "earthen Kang”. It is difficult to explain this phenomenon by chance coincidence, which should be the result of folk stories spreading and traveling across regions.

From the perspective of characters (story characters), the similarities between the two stories are also very obvious. The list is also compared as follows:

\begin{tabular}{|l|l|}
\hline A nest of wild eggs & The old man took the old woman’s seven daughters with him \\
\hline Old man and old woman & Old man and old woman \\
\hline Four daughters & Seven daughters \\
\hline Ye Hu Sister & Mao Ye woman \\
\hline Grandma & No correspondent plot \\
\hline
\end{tabular}

It can be seen that in addition to the lack of the "old granny" as a helper in Donggan story, the other groups of characters in the two stories are completely corresponding, the difference is only in the number of daughters and the identity of a ferocious opponent. In terms of ferocious rivals, the similarities between the wild fox sisters and the wild woman are also obvious: both are women; In the name all contain to express the ferocious "wild" word; Have a hobby for cannibalism.

It is worth mentioning that the story of the "Mao Ren" spreading in northwest China and the Donggan region of central Asia reminds us of the "Mao Ren clutch women" in the seventh volume of Zi Bu Yu written by Yuan Mei in the Qing dynasty:

In the northwest, woman did not use any device for urinating. There was Zhao's wife in Xianning county, Shaanxi province. She was over twenty years old with fair complexion and beautiful body shape. In the middle of summer, she went to the field to empty her bladder but didn't come back for a long time. Her husband heard some noise from the wall and starred at that side. He saw his wife half-naked climbing the wall with two feet outside the wall and two hands hanging in the wall. So he helped her immediately. His wife could not speak. He opened her month, and cleared the mud in her month and her began to be able to talk, "I went out to pee, when I just took off my trousers, I saw a big furry man with his eyes sparkling and waving at me. I was in a hurry to run away, the hairy man stretched out his huge hand from the wall and pulled me up to the top of the wall. He put mud in my mouth and dragged me out of the wall. My two hands held the wall, now exhausted, luckily you rescue me quickly.” Zhao looked outside, there was exactly a big hairy man who looked like monkey but was not a monkey, crouched at the wall, with his both hands holding the wife's feet tightly. Zhao held his wife's body and pulled, but he was beat by the giant, so he called the village neighbors. But no one responded him as the neighbors lived fa away from him. So he went inside to take a knife to cut the fairy man's hands and save his wife. But when he took the knife, his wife was pulled by the giant outside the wall. So Zhao opened the door and ran outside to catch him. His neighbors also came. The furry ran so fast like the wind, taking the wife away. The wife's cry for help was especially loud. They ran for twenty li, but still couldn't catch up with him.

In the next morning, they follow the footprints to a big tree where they found the wife dead: her limbs was bind with giant vines. There was mark of teeth biting on her lips. Her pudendum was teared where even bone 
could be seen. Layers of white sperm covered on her blood. All the village neighbors were crying and reported to the official. The official also cried when they saw and buried her properly. The official call for hunters to catch the furry man but they failed. ${ }^{3}$

Although the "wild fox sister" in the story of Gansu province and the "hair wild woman" in the story of Donggan are both female and the "big hairy man" in the story of Zi Bu Yu are male, the plot and content of the two kinds of stories are also quite different, but it is still not difficult to find the common characteristics of the main characters in the story: Hairy and ferocious. In addition, the place where the story takes place is Xianning county, Shaanxi province, which was under the jurisdiction of Xi 'an government in the Qing dynasty. In the period of the republic of China into Xi 'An Changan county (now Chang 'an district). In today's shaanxi province guanzhong, north shaanxi, south shaanxi three regions, have "fairy man” story spread. Combined with literature and field data, it can be inferred that the communication center of "fairy man" story is probably in central Shaanxi plain.

To sum up, the author thinks that the Longdong folk story "A nest of wild eggs" and the Donggan folk story "The old man took the old woman's seven daughters with him", although there are many differences in details, but the plot, the role of the high degree of similarity, indicating that the two have a deep origin. Considering the historical migration activities of Donggan people, it is reasonable to believe that such stories originated in the Shaanxi region of China and spread to Gansu, Ningxia and other places, and then spread to the Donggan community of central Asia with the migration of the northwest Hui nationality. Since then, different derivatives have been developed in the inheritance of the two regions.

\section{Story of Pan Leakage}

Along with the migration of Donggan people from northwest China to central Asia, there is a story called "pot leakage". Such stories are widely spread at home and abroad. They are included in the "Chinese folk story type index" compiled by Chinese-American scholar Ding Naitong and Taiwanese scholar Jin Ronghua. This type of story was also picked up by Soviet scholar m. Hasanov in Kyrgyzstan in the 1950s. Story highlights: Once upon a time there was an old man and an old woman. The old woman used to say to the old man in conversation that her greatest fear in the world was the "leaky pot". At this time there was a thief on the roof, wanted to steal the old man's calf, just heard the old man and the old woman talk. As it happened, a tiger heard the conversation, and wanted to drag the calf away, too. The thief fell off the roof onto the tiger's back. The tiger thought, it must be a "pot leak" fell on himself. The thief did not know the tiger, but also mistakenly thought that he fell on the "pot leakage" body. The frightened tiger ran away with the thief on its back. The thief took the opportunity to climb a tree to escape. A monkey got the idea and persuaded the tiger to go back to eat the "leaky pot". But unexpectedly by a strange combination of circumstances, the monkey became the tiger's good meal.

In the collection of Chinese folk stories, Shaanxi volume, published in the 1990s, there is a story circulating in the Tongchuan area of Shaanxi province, entitled "the pot leakage baby cries", ${ }^{4}$ which is similar to Donggan folk tales. The plot is as follows: Two country women were digging for wild vegetables. One said she was not afraid of wolves, insects, tigers and leopards all her life but afraid of "pot leakage baby cry". But their words were heard by a tiger in the forest. That night, a thief went to a house to steal a donkey. He tied the

\footnotetext{
3 Yuan mei: Zi Bu Yu, Complete works of Yuan Mei (vol. 4), Nanjing: Jiangsu ancient books publishing house, 1993 , p. 134.

4 This story also spread in Gansu and Ningxia. The author found out the Gansu story in the field survey in Longdong region; For Ningxia stories, please refer to "Guo Er Lou" in collection of Chinese folk tales, Ningxia volume.
} 
donkey to a tree in front of the door and went in to steal something else. When the tiger came to the village to look for food, the donkey heard the tiger's voice and broke its bridle and ran away. The thief mistook the tiger for a donkey and rode it north. The tiger was surprised, thought he met a "pot leakage baby cry", carrying the thief also rushed to escape, the thief was thrown down. The tiger panted and ran into the woods. The monkey saw the tiger and asked him the reason for his panic. The tiger told himself that he met a "pot leak baby crying". The monkey threatened to avenge the tiger and went out of the woods and saw two legs under the tree (that is, the thief's legs) then disappeared. So the monkey went back to tell the tiger, "pot leakage baby cry" climbed on the tree, and volunteered to catch him. The monkey went up the tree and saw that there was no monster, but a man. When the thief saw the monkey coming up, he was so scared that his urine ran down his pants legs and right into the monkey's eyes. The monkey had to blink. The tiger thought the monkey winked at him and ran away. The monkey somehow ran away too. The tiger was running when he met the bear. The bear made haste to inquire after the tiger. The tiger told what happened last night and just now. The bear also offered to avenge for tiger, but the tiger had already experienced once, and he lay on the ground shaking his head. The bear had no choice but to suggest carrying the tiger on his back. When they uust went to the tree, the thief has not yet come down from the tree thinking that the bear and tiger cooperate to eat him, he came up with a plan in panic, and shouted at the bear: Your father promised to give me three tiger skins three years ago. Why only one today? When the tiger heard this, he thought the bear was lying to him. He slipped off the bear's back and ran off into the deep woods. ${ }^{5}$

Compare the two stories, the basic plot is highly similar, are two women chat, lead to "pot leakage" or "pot leakage baby cry"; A thief steals a calf or a donkey at night and accidentally fell on the back of a tiger, who mistook it for a monster two women were talking about during the day. The difference is that in Donggan's story, the monkey takes all the credit to the tiger and is eaten by the tiger. In the Shaanxi story, the monkey follows the tiger and runs away. In addition, the ending of the Shaanxi story has one more plot element than the Donggan story: After the monkey escapes, the bear appears, and the plot pattern is a repetition of the monkey story.

According to Li Fuqing's research, these types of stories come from the ninth story in the fifth volume of the Five Books of India. The Indian story tells of a horse thief who drags out of the stable the Rashtra who turned himself as horse and hide in the stable. But the Rashtra regarded the horse thief as a terrible monster. Just like the "pot leakage" in Donggan and Shaanxi stories, the strange word "vijaro" (meaning "evening") heard by Rashtra plays an important role in Indian stories. Ratha mistook "vijaro" for a monster more powerful than himself. The story is also popular in northeast Asia, including Japan and the Korean peninsula. There are more than 70 different derivates found in Japan alone. ${ }^{6}$ However, considering the close relationship between donggan people and northwest China, and the high similarity between the above two stories, the author believes that, the story of "pot leakage" spreading among Donggan ethnic groups is a variation of the story of "pot leakage baby crying” in Shaanxi, Gansu, Ningxia and other places, and its source is still in northwest China.

\section{Story of Ganluo}

In the Collection of Donggan Folktales and Legends compiled by Li Fuqing, the 48th "Rooster's Egg"

\footnotetext{
${ }^{5}$ See Shaanxi volume of Chinese folk tales, Beijing: China ISBN center, 1996, pp. 432-433.

${ }^{6}$ Li Fuqing: Collection of Donggan Folktales and Legends, translated by Lian Shusheng, Shanghai: Shanghai literature and art publishing house, 2011, pp. 503-504.
} 
belongs to the witty character story. The story is as follows:

A Lord gave orders to his officers: "Get me two rooster's eggs, and I'll eat them. I'll give you three days, and if you can't give me after three days, I'll beat you to death." "Where can I find this?” the officer was depressed. He went back without eating, drinking tea or talking. His wife asked him, "why are you so worried?” He was silent. His wife kept asking. He said: “Ah, master told me to find him two rooster's eggs. I'm worrying about that.” "Don’t be afraid,” said his wife. "in three days I will go to see the master.” Three days passed, and she came to the master. The master asked her, "what did you do here? Where is your man?" The wife said, "Sir, my man has a baby.” The Lord said, "shame on you! Hou can a man give birth to a baby?” The wife also asked him, "which rooster lays the eggs?” The master said nothing.

Although the protagonist in the above story has no name, the plot structure of the story and the way the hero deals with the difficulties created by his boss are exactly the same as the folk stories spread in northwest China. stories with witty character Ganluo as the core spread in Shaanxi, Gansu and other places. It is said that Ganluo was the grandson of Ganmao, the famous minister of the state of Qin during the warring states period. At the age of twelve, Ganluo was sent to the state of Zhao. With his wisdom, he won more than ten cities for the state of Qin without a single soldier and was awarded Xia qing title by the King of Qin, Yingzheng. Although there are few records about Ganluo in the historical books of all dynasties, the folk people are fond of talking about many "deeds" of which the source is unknown.

In one of the stories in the series story of Ganluo: Once, when his grandfather came back from court feeling very unhappy, his family asked him the reason. He replied that the emperor had given him three days to present a rooster's egg, or else he would be put into prison. When the family heard about it, they didn't know what to do. Ganluo then stood up and asked to go to court for his grandfather and help him. The next day, Gan Luo went to court, the emperor asked: why your grandfather did not show up? Ganluo replied that grandfather is in confinement. The emperor felt strange: how can a man be in confinement? Ganluo asked: how can a cock lay eggs? Emperor was speechless, Ganluo’s grandfather successfully overcome difficulties. ${ }^{8}$

Although the characters in the story of Donggan are "master", "officer" and "officer's wife", the difficulties in the story, as well as the way and tone of the heroine to solve the problems, are highly consistent with the Ganluo's story spread in northwest China. It can be inferred that the aforementioned Donggan witty character story was mostly transplanted from the Ganluo story which was spread in China.

\section{Donggan Folktales’ Borrow from Northwest Folk Tales}

There is another phenomenon in Donggan folk tales: a "plot unit" in the story, whose mode is very similar to that of folk tales in northwest China, but the specific characters and plot structure of the whole story are obviously different from those in northwest China. In addition, this kind of "plot unit" has a strong regenerative function and can be repeated in various folk stories to form different plots. From the Angle of story science, this kind of "plot unit" is the motif. ${ }^{9}$ It is concluded that the above types of Donggan folk tales are the product of the motif of folk tales in northwest China. In other words, this type of folktales is not a direct "transplant" of

\footnotetext{
7 Ibid., p. 198.

8 The story is spread in Qishan county, Shaanxi province. It is told by Wen Dong, a 20-year-old college student.

${ }^{9}$ Motif is an important term in folk literature. To the knowledge of the author, Hu shi first translated it into its current name. It is generally believed in academic circles that motifs are similar to morphemes in linguistics and phonemes in phonetics, and they are indivisible minimum plot units in folk stories and can be combined with other motifs to form new plots. This article uses the concept in the same sense.
} 
northwest China's folktales in central Asia, but a new story created by combining the motif of northwest China's folktales with other motif or plots. In the Collection of Donggan folk Tales and Legends compiled by Li Fuqing, there are many folk stories in this situation. The author only gives three kinds of motifs for investigation.

\section{Throw Embroidered Ball to Choose Groom}

"Throw embroidered ball to choose groom" is a common motif in traditional Chinese operas, novels and folk tales. The story that contains this kind of motif usually tells about: the young lady of some large family arrived marriage age. The parents held ceremony at the embroider building to choose a young husband for the daughter. At that time the young lady holds embroider ball, after finding the suitable husband in the crowd of downstairs, throw embroider ball to him.

Although the plot is well known in China, it is influential that similar scenes can still be seen from time to time in current TV and film works. However, it is certain that in the Han dynasty, which stresses on "the order of parents and the words of matchmakers", the phenomenon of "choosing husband by throwing embroidered ball” could not exist in ancient times. There are few records of this custom in the official history. Some scholars, with the help of field data, believe that this custom may exist among the ancient southwest minorities, and was absorbed by the novels and operas of the Han nationality due to its dramatic effect. ${ }^{10}$

Because this plot has a strong function of "regeneration", it can be absorbed by different works or combined with other plots to form new works. Therefore, from the perspective of motif, the author believes that this plot conforms to the characteristics of "motif" and can be regarded as a literary motif.

From the perspective of northwest China, the most famous operas and folk stories involving the motif of "choosing husband by throwing embroidered ball" are the legends of Wang Baochuan and Xue Pinggui. It is worth noting that the plot in this story is very similar to the Donggan folk story Zhang Tianyou:

The emperor discussed with his concubine to make some embroidered eggs so the daughters can get married. The next day, people waited below the emperor's throne room. When will three girls of the emperor throw embroidered eggs? The elderly daughter threw embroidered egg to the head of army officer. The second girl threw it to the emperor's number one scholar. The third daughter didn't throw the embroidered egg for two days. The emperor asked who didn't get chose? At that time, Zhang Tianyou and a blind guy were wandering on the street and supervised. The emperor was told that: the bald guy and blind guy were wandering on the street." The emperor ordered: "Let me have a look" and sent people to bring them to him. But there were so many people, they couldn't walk through. Zhang Tianyou was playing in the mud and run away among the crowd. As people thought Zhang was dirty, they stood aside for him. Zhang Tianyu came to the the throne room. When the emperor's third girl saw the bald man, she threw the embroidered ball in his arms.

The emperor turn his ashamed face and went in him room. The emperor had placed his two eldest sons-in-law in the throne room. Put the third girl and her little son-in-law in a scrap yard in front of the stable. ${ }^{11}$

Compared with the legends of wang baochuan and xue pinggui, the above story apparently absorbs the characteristics of "witty character stories" (such as Zhang Tian's extraordinary method of "rolling into mud balls" to squeeze into the crowd). But the similarities between the two stories are also clear. Not only does the

${ }^{10} \mathrm{Gu}$ Jiegang. “the First Edition of Shi Lin's Miscellaneous Knowledge.” Beijing: Zhonghua publishing house, 1963, pp. 111-120.

${ }^{11}$ Li Fuqing: Collection of Donggan Folk Tales and Legends, translated by Lian Shusheng, Shanghai: Shanghai literature and art publishing house, 2011, p. 63. 
formula of the embroidery house look the same, all the third daughter took a fancy to poor guy. And there are many overlapping in characters' identities: in Donggan story, the son-in-law is a military officer, the second son-in-law is a civilian, the third son-in-law that got “embroidered eggs” is a beggar; in Wang Baochuan's legend, the prime minister's son-in-law Su Wen was a civilian, the second son-in-law Wei Hu is a military officer, the third son-in-law Xue Pinggui was also poor. In addition, the two stories have very close endings: In donggan's story, the emperor punishes the third daughter by placing her and her third son-in-law in a small room in front of the stable. In the legend of Wang Baochuan, Wang Baochuan insisted on marrying Xue Pinggui, a poor beggar, and even broke kinship with her father, the prime minister, by clapping hands with him, then lived with Xue Pinggui in a shabby kiln at the south of Chang'an City.

In the author's opinion, like other folk tales in Donggan, the origin of "choosing husband by throwing embroidered ball”, as a kind of story motif with profound Chinese culture, is probably also in China. When Donggan ancestors lived in Shaanxi in their early years, they heard and heard Wang Baochuan and Xue Pinggui's drama and legend; After he moved to central Asia, it was transformed into Donggan's unique language art "songs" with Wang Baochuan as the core image on the basis of Chinese legend. In addition, the motif of "choosing husband by throwing embroidered ball" was borrowed and combined into the story of Donggan's "witty character" after processing and adaptation, and finally, Donggan folk tales with central Asian characteristics and traditional Chinese culture were created.

\section{Advise Marriage by Allegory}

There is also a common motif in the folk tales of central Asia, Donggan and northwest China, about a woman has passed the age of marriage, but the father for a variety of reasons didn't want his daughter get married; a woman or another man one day persuaded his father in a metaphorical way, the father was inspired to let his daughter get married. The author calls this kind of motif as "advise marriage by allegory". There are two key elements to identify this kind of motif. One is that the woman is old, but her father is still unwilling to let her get married; The second is that the protagonist did not directly persuade his father, but used euphemistic means to make him realize his fault, and finally accepted opinions with full conviction.

In the foregoing story of Zhang Tianyou, there is a plot in the middle, which belongs to the motif of "advise marriage by allegory" mentioned above. Zhang Tianyou in the story is the poor child from humble family. He wanted to escape the persecution of stepmother and her lover, he came to palace and worked for the emperor, and became adopted son for the old man who planted melon for the emperor. Although Zhang Tianyou was from a humble background, he was quite intelligent and could admonish the emperor by tactful ways. Once, the father went to the palace to send watermelon, Zhang Tianyou specially picked three watermelons from the ground, wrote respectively the names of three girls on the melons, and asked his father distribute the watermelon to the three girls by name. After the old man entered the palace, the emperor asked his three daughters to cut up their watermelons. As a result, the watermelons of the first girl and the second girl was rotten, while the watermelon of the third daughter was sweet and sandy. The emperor investigated, the old man had to let Zhang Tianyou explain to the emperor. Zhang Tianyou entered the palace and told the emperor: The eldest daughter, the second daughter is too old to marry, just like the watermelon has missed the sweet and sandy season; Only the third daughter was a the right age. If she did not marry soon, she would become as bad as a watermelon. When the emperor heard this, he told his three daughters to get married quickly. 
Motifs similar to "advised marriage" can be found in folk tales of northwest China. The author collected and recorded a story in Gansu province about a woman who was old and her father is a rich man. Her father did not want his daughter to marry for selfish reasons. On one occasion, the woman was feeding the dog when she deliberately sprinkled flour on the dog's head in front of her father. The father scolded his daughter: why so careless, waste food? The woman answer: people still want the dog even it has white hair, but nobody wants someone with white hair (gets old). The father heard, thought it was reasonable, and had to let her get married. $^{12}$

From the perspective of Zhang Tianyou, the Donggan story is long in content and rich in plot, which is obviously different from the stories of Han nationality in China. Among them, there are motifs from central Asia and Chinese culture. Like the hydra in the story, its life was hidden in a box on the top of a tree. This is a typical "horcrux" motif. It was very common in folk narratives of northern nomads with shaman beliefs and must have come from central Asia, where the Donggan live. However, in terms of "advised marriage”, although there are great differences between the two stories, the basic pattern is still the same. The content involves women's marriage, and indirectly admonition to the woman's father, so it should be the motif from northwest China.

\section{Escape Disaster by Exchanging}

Donggan folk tale tales of "immortals sells words" is a typical composite story. With the protagonist's journey, a series of short stories are embedded in the big story frame. The main story was about a honest man named "honesty" on his business trip, met a strange old man Shouting "sell words" along the street. "Honesty" heard, without hesitation to pay for words. The old man after receiving money speak a series of taboo for Honesty to pay attention in the future. The young man acted cautiously according to the old man's instruction and avoided every danger. Each taboo leads to a danger; Each dangerous occurrence and dissolve respectively constitute a small story. In this way, the "tandem compound" structure common in Arab folktales was formed. The above stories are widely spread at home and abroad. In the Index of types of Chinese folk tales compiled by Ding Naitong, the number 910 is "warnings bought or provided by others prove to be correct"13 is a summary of the above story types. Among the many small stories embedded in the "major story" is as follow:

After a few days walking, Honesty came to a castle. He was tired of walking and thought about where to stop for the night, then suddenly he remembered his brother's house. His brother opened a furniture kiln here, so he hurried to his brother's house. Brother was very happy to see his brother and asked his brother, where he came from. Honesty told him about the business. Brother was silent, then late at night, he discussed with his wife to burn honesty. He said, "everyone says that in a china kiln, the china is not good without burning one person. Tomorrow when we send meal to the kiln, we ask Honesty to send. I will tell the staff in the kiln that whoever come tomorrow, just put him in the kiln and burn him to death. His wealth is left over for us, so that we can save it for our son to get a wife.” The elder brother conspired with his wife and decided to do so. So they made the meal next day. His sister-in-law said to Honesty, "brother in law, can you take the meal to the kiln?” Honesty said yes and took burden of the meal. On the way, he saw a man with white beard was telling story. He remembered what the immortals had said, he would stand among the crowd and listened. Just then his

\footnotetext{
${ }^{12}$ This story is collected and recorded by the author in Liangyi township, Zhuanglang county, Gansu province. The narrator is Su Tianliang, male, 54 years old, a farmer.

${ }_{13}$ Ding Naitong. Index of types of Chinese folk tales, translated by Zheng Jiancheng, et al., Wuhan: Central China normal university press, 2008, p. 193.
} 
brother's son came and found the Honesty and the people were listening to the storytelling. The son of the elder brother asked: “uncle, why you didn’t send a meal?” Uncle replied: “I was listening to the storytelling and forgot to send the meal."

Nephew didn't want to ask his uncle to leave and said: “uncle, you listen to the storytelling, let me send the meal.” Honesty accepted. Hi nephew took the burden and brought food to the kiln. When the man in the kiln saw the owner's son coming, he did not mean to push the owner's son into the kiln, but he was afraid that the owner would have trouble with him. So people worked in the kiln didn't care about the son of the owner, and all of a sudden pushed the son to the kiln and burned him to death. ${ }^{14}$

The whole story conveys the idea that good and evil are rewarded in folk literature. The content naturally does not stand up to scrutiny. However, the motif involved in the story, that is, because of the exchange of a token and lead to the murder of the mastermind's relatives (or confidants), can be found in many Chinese and foreign works. The most famous of these is Shakespeare's tragedy Hamlet. The play tells the story of the king wanted to kill Hamlet by the hand of others, specially sent two trusted companions to accompany Hamlet to send a letter to the king of England, and to tell the king when he sees the letter immediately executed Hamlet. But on the way, Hamlet read the letter, and forged a letter that asked the king to kill the two messengers immediately. So he changed the crafty king's letter, the trusted followers of the king were killed, and Hamlet escaped from danger. ${ }^{15}$

The motif above also exists in folk tales of northwest China. A story collected and recorded by the author in Gansu tells: Stepmother is mean to her stepchild. Once she asked biological and non-biological children go to the mountains to plant hemp seed and whose seed grow first could come home first. Stepmother gave biological son raw hemp seed, and fried hemp seed to non-biological son. Walking on the way, two brothers tasted hemp seed, younger brother said: "brother, your hemp seed is fragrant but mine is not, why?" The elder brother say: "that we two change the seeds." As a result, what the elder brother planted grew, and what the younger brother planted did not grow. The younger brother was afraid of going home, stayed in the mountains, and finally became a bird, called "hemp seed brother." ${ }^{16}$ From the perspective of genre, this folk narrative is a folk tale, but its plot structure fully conforms to the common motif of "switch to avoid disaster" in folk tales. By comparing the folk tales of Donggan and Shakespeare's plays with those of northwest China, it is not difficult to see that Donggan's story is more similar to Gansu's story in the treatment of the same motif. The mastermind and victim is mother and son (father and son); There is a kinship between the target and the ultimate victim. In addition, the items exchanged by the two sides are all articles (in Donggan story, it is the burden of food delivering, while in Gansu story, it is hemp seed). Letters rather than relating to writing are more characteristic of folk narratives. It can be inferred from the above that as the ancestors of Donggan people moved to the west, the motif of this story spread from northwest China to central Asia and was combined with other plots to form a new story.

\footnotetext{
${ }^{14}$ Li Fuqing: Collection of Donggan folk tales and legends, translated by Lian Shusheng, Shanghai: Shanghai literature and art publishing house, 2011, p. 128.

15 Shakespeare: Hamlet, complete works of Shakespeare (Vol. 9), Translated by Zhu Shenghao, Beijing: People's literature press, 1978, pp. 130-131.

${ }_{16}$ This story is recorded by the author in Yongning township, Zhuanglang county, Gansu province. Narrator: Liu Bielai, female, 69 , a farmer.
} 


\section{Conclusion}

As a descendant of hui immigrants in northwest China in late Qing dynasty, Donggan people are closely related to Chinese culture. Although surrounded by central Asian cultures, Donggan people still retain many cultural traditions of northwest China due to differences in language and customs. They tell the dialects of Shaanxi and Gansu provinces in China, and they also inherit a large number of folk literature from northwest China. Due to the limited space, this paper only takes folk stories as the object, selects several typical cases, and through the comparative analysis of plot structure and story motif, investigates the spread of northwest Chinese folk stories in the Donggan region of central Asia. In general, Donggan people, based on their own cultural memory, have directly transplanted, transformed and borrowed folk stories from northwest China, and created a unique Donggan folk story on this basis.

\section{References}

Yuan mei: Zi Bu Yu, Complete works of Yuan Mei (vol. 4), Nanjing: Jiangsu ancient books publishing house, 1993 Shaanxi volume of Chinese folk tales, Beijing: China ISBN center, 1996.

Li Fuqing: Collection of Donggan Folktales and Legends, translated by Lian Shusheng, Shanghai: Shanghai literature and art publishing house, 2011.

Gu Jiegang. “the First Edition of Shi Lin’s Miscellaneous Knowledge.” Beijing: Zhonghua publishing house, 1963.

Ding Naitong: Index of types of Chinese folk tales, translated by Zheng Jiancheng, et al., Wuhan: Central China normal university press, 2008.

Li Fuqing: Collection of Donggan folk tales and legends, translated by Lian Shusheng, Shanghai: Shanghai literature and art publishing house, 2011.

Shakespeare: Hamlet, complete works of Shakespeare (vol. 9), Translated by Zhu Shenghao, Beijing: People’s literature press, 1978. 